\title{
Percursos e trajetórias: a identidade do diretor de escola negro nas escolas municipais da cidade de São Paulo
}

Douglas Aparecido de Campos a Maria Angélica Chagas Ferreira ${ }^{b}$

\section{Resumo}

Esse artigo é o resultado da pesquisa realizada na área da Educação que teve como base o estudo de um fenômeno social no âmbito escolar e investigou a trajetória identitária do diretor de escola negro em escolas municipais na cidade de São Paulo. Utilizamos o método de história oral, com as técnicas de entrevistas e análise dos depoimentos. Organizamos três categorias de análise, são elas: família e representatividade; formação docente e gestora; e identidade étnica e o fazer administrativo na escola. Concluímos que o racismo é vivenciado e enfrentado pelos diretores de escola e que conseguem, apesar dessa realidade, desenvolver trabalhos relevantes para a comunidade onde atuam sem se vitimar. A identidade étnico-racial torna-se um instrumento de luta para legitimar elementos fundamentais de constituição de sua identidade profissional.

Palavras-chave: Negro. Diretor de Escola. Identidade. Políticas de Ação Afirmativa.

\section{Introdução}

A cotidianidade hierarquizada na contemporaneidade atribui um grau de poder aos gestores administrativos, principalmente, aos que estão na função de direção de uma entidade. A sociedade patriarcal (SANTOS, 2010) atribui notoriedade a esses cargos, por conta do alto poder de mando, o que lhe confere também um alto poder de status social. Ainda dentro desse contexto patriarcalista, notamos a ocupação de uma maioria de pessoas brancas em cargos gerenciais. A pesquisa do Instituto Brasileiro de Geografia e Estatística - IBGE (2020) sobre "Desigualdades Sociais por Cor e Raça no Brasil", datada de 2018, afirma que apenas $29,9 \%$ de pretos e pardos ocupam esses cargos, enquanto $68,6 \%$ são ocupados por brancos. Nessa

\footnotetext{
a Universidade de São Carlos, São Carlos, SP, Brasil.

b Universidade de São Carlos, São Carlos, SP, Brasil. 
pesquisa não aparece o recorte por gênero, porém, outros dados, como nível de escolaridade, trabalhos informais e acesso a cargos políticos, nos mostra que as mulheres negras ganham menos que as mulheres brancas e sugere que a porcentagem em relação à ocupação dos cargos de gerência ou de diretoria é pequena.

Quando observamos a visibilidade de negros em cargos de chefia podemos verificar que ela é percebida negativamente quando se avalia a competência profissional. Quando pessoas da comunidade e responsáveis pelas crianças, que ainda não conhecem o gestor, vão à escola e, ao serem recebidos pelo diretor/diretora negro (a), desenvolvem o seguinte diálogo: "Quero falar com a diretora", diz a pessoa que chega para ser atendido na secretaria da escola. $\mathrm{O}$ diretor/diretora negro que a atende diz: "Sou eu, posso ajudar?". E a pessoa, com toda incredulidade possível, insiste: "Por favor, chame a diretora", mas, entra uma outra pessoa na secretaria e diz: "Esta que está te atendendo é a diretora". O constrangimento se afirma com o pedido de "desculpas" e a fala: "Eu não sabia".

Durante a pesquisa alguns autores nos ajudaram a refletir, porque será que essa cena acontece: Será a aparência? (NOGUEIRA, 1985, 1998). Será diferente um diretor? (SILVA, 2014), ou, ainda, o formato e a ideia tradicional que temos de uma escola não poderia ter um diretor diferente do imaginário social (PARO, 2010, 2011)? Ser mulher, negra e diretora é desconstruir estereótipos (GOMES, 1995, 1996)? Modelos institucionais criam barreiras para que pessoas diferentes exerçam funções como as de chefia ou liderança (ALMEIDA, 2019)?

A identidade étnica e profissional foi a base estruturante da pesquisa. Contamos com o auxílio de autores como: Dubar (1997, 2012), Heller (1970), Paro (2011, 2015), Santos, BS (1999, 2003, 2010), Vazquez (1977), que subsidiaram as discussões e as análises do que é ser diretor de escola de Educação Básica com os atributos da cor e de gênero em um país ainda racista e preconceituoso. Nesse sentido, algumas questões surgiram e desencadearam a nossa questão de pesquisa, dentre elas, citamos: o diretor de escola é cargo de chefia, mas, quando esse cargo é exercido por uma pessoa que se autodeclara negra há alguma diferença? A comunidade escolar o percebe da mesma maneira como perceberia um diretor(a) branco(a)? Ser mulher, negra e da comunidade escolar cria expectativa diferenciada das pessoas? Como é para esse diretor escolar negro estar numa comunidade em que muitos estudantes também são negros, isso auxilia no processo de representatividade social?

Formulamos, então, a seguinte questão de pesquisa: "Como é a trajetória identitária do diretor de escola negro quando esse está num processo de assunção de um 
cargo de chefia em escolas municipais na cidade de São Paulo?" Discutimos o processo de construção de sua identidade étnico-racial e profissional para verificar se essa visibilidade adquirida com o ingresso no cargo de chefia é percebido negativamente quando se avalia sua competência profissional.

Nesse contexto, solicitamos junto ao Comitê de Ética o pedido de autorização para realização da pesquisa e tivemos a aprovação necessária para o estudo.

\section{Identidade em processo no cargo de diretor de escola}

Ligada a estruturas discursivas e narrativas, segundo Silva (2014), a identidade é instável, contraditória, fragmentada e inconsistente, mas se estabelece em meio a um processo de produção social que envolve relações de poder. A definição de identidade, como sendo aquilo que se é, demonstra uma incompletude: não se é sem o outro, sem contexto, sem representação, assim:

A identidade é um processo em constante progressão e transformação e, por essa razão, o sujeito não está preso a uma única identidade, ao longo da vida, fixa e imutável; antes, ele transita constantemente através de múltiplas identidades, as quais são instáveis, processuais e frequentemente efêmeras (ZUBARAN; WORTMANN; KIRCHOF, 2016, p. 18).

Observamos que a identidade é percebida pelo sujeito por meio da realidade social em que vive em relação às expectativas sociais e à transposição ou à superação que o sujeito alcança com a possibilidade de estudar e aprender sobre si, sua história, sua realidade e de reivindicar seu espaço, ou, como afirma Ribeiro (2017), sua localização social. O percurso dessa construção é marcado por dificuldades, escolhas, saberes e vivências que cada sujeito, a seu modo, encontra nas representações: simbólicas, históricas e vividas, num movimento constante, marcado pela busca individual e coletiva de encontrar seu espaço e seu lugar social.

Aí eu falo, a gente que é negro, infelizmente, a gente encontra uma barreira ainda maior, porque... muita gente olha para gente, porque é assim... não falaram na minha cara, mas assim..: o que você está fazendo aqui? Aqui neste lugar? E às vezes as pessoas, como eu falei, às vezes elas têm consciência, mas não fala na sua cara. Assim, você encontra uma barreira ainda maior, para que te enxerguem como líder (Relato do Diretor 4, 2019). 
Santos (1999) afirma que as políticas de identidade são difíceis de concretizar, pois as sociedades operam com sistemas desiguais e excludentes, característica das sociedades capitalistas. Por isso, sistemas de inclusão e exclusão dividem a sociedade, categorizam grupos e organizam movimentos em busca de acesso a bens e a lugares. Observamos isso na fala do Diretor 4.

\section{O racismo e as políticas de ação afirmativas}

O preconceito racial é um juízo de valor e uma expressão negativa. A sociedade brasileira e sua história são marcadas pelas diferenças étnicas e pela hierarquização invisível dessas diferenças. Nogueira (1998, p. 195) afirma que "o preconceito racial é parte constitutiva do sistema ideológico desenvolvido pelo grupo branco, e tem, por função, a preservação de sua supremacia social ante os demais elementos da população". As falas e as ações descritas pelos entrevistados trazem esses diversos sinais de preconceito racial que se "naturalizaram" no cotidiano.

Ser negra não é fácil, pois eu não aceitava ser rebaixada por causa da minha cor, sempre fui muito comprometida com o meu trabalho. Quando entrei nessa escola que trabalhei por 16 anos, peguei a turminha do maternal, a dona da escola gostou do meu trabalho, e no ano seguinte fui mostrando como trabalhava, e no terceiro ano que estava lá, a professora do pré 3 saiu, e essa turma ficou sem professor, uma turma importante para manutenção e continuidade da escola. A dona da escola sabia do meu trabalho e do meu interesse em ficar com essa turma, inclusive o Coordenador chegou a colocar meu nome num papel e mostrar a ela, porém ela não me deu a turma. Fiquei pensando "porque ela não me quis com essa turma, será que era por causa da minha cor, pois essa turma tinha formatura no fim do ano e talvez ficasse estranho uma professora negra" ou "porque ela ainda não acreditava na minha competência para pegar essa turma", continuei com a turma do maternal naquele ano, trabalhando muito e mostrando que eu era boa sim o suficiente para pegar essa turma. E no ano seguinte a dona da escola enfim me deu a turma, mas tive que provar que eu era capaz (Relato da Diretora 2, 2019).

Ser negro, nessas condições, é estar em constante luta para uma autoafirmação social, é uma busca de pertencimento. A definição desse conceito representa a perspectiva de denúncia, de resiliência e de resistência, assim como os diretores escolares negros nos relataram. 
Hall (2013) afirma que ser negro não é apenas uma categoria, uma personificação de uma imagem, mas é algo maior: ser negro é estar num contexto arraigado de cultura, de história, de diferenças, de estrutura, e na necessidade de desconstruir a lógica racista. É importante destacar o papel da escola na Educação da representatividade, na possibilidade da criança, do jovem, se perceber em condições de almejar inserção social em todas as esferas sociais.

Ao observar o racismo marcado por um comportamento assentado na perspectiva da invisibilidade e da inferioridade, desrespeitoso e vexatório em relação ao pertencimento racial e/ou características distintas do indivíduo ou grupo ao qual pertence, Gomes (1995, p. 54) afirma:

O racismo é, por um lado, um comportamento, uma ação resultante da aversão, por vezes do ódio, com respeito às pessoas que possuem um pertencimento racial observável através de sinais diacríticos tais como: cor da pele, tipo de cabelo, etc., e por outro lado, é uma ideologia, uma doutrina referente às raças humanas na qual postula-se a existência de raças superiores e inferiores. Ele resulta da vontade de se impor uma verdade particular como absoluta, por exemplo: as doutrinas raciais surgidas no final do século XIX aqui no Brasil serviram para justificar a escravidão e exclusão negra.

A situação do negro no Brasil, em várias pesquisas observadas (Boletim NegroSeade 2017¹, RAIS 2013-MTE [DIEESE, 2014], entre outras), são de desigualdades e muitas delas de elevada diferença. Os movimentos negros e as organizações étnicas lutam por equiparação legal e social. Os negros, ao tentarem interagir e conquistar espaços, lutam para que suas competências e conhecimentos adquiridos enalteçam e superem as questões de raça e de cor.

A história do Brasil é marcada pelas histórias de povos e de raças que, infelizmente, nos parece serem contadas a partir de perspectivas únicas, ou seja, pelo olhar dos colonizadores. Munanga e Gomes (2016, p. 11) nos ajudam ao afirmar que no Brasil há muitas características e todas elas parecem não dar conta da realidade, que é tão complexa, assim:

Aprender e conhecer sobre o Brasil e sobre o povo brasileiro é aprender a conhecer a história e a cultura de vários povos que aqui se encontram e contribuíram com suas bagagens e memórias na construção deste país e na produção da identidade brasileira.

\footnotetext{
1 https://www.seade.gov.br/produtos/midia/2018/11/Boletim_negro_2018.pdf. Acesso em: 23 jun. 2019.
} 
A história do povo negro sempre foi de exclusão e de luta, os movimentos sociais, em busca de direitos, lutam há mais de um século para que algumas políticas de reparação sejam promulgadas, leis que garantam dignidade, trabalho e direitos. Segundo Ferreira (2019), no Brasil, a democracia enfrenta obstáculos, pois há uma distância entre a lei e sua efetividade, além da tradição preconceituosa e discriminatória e a negação do racismo que têm como consequência as injustiças sociais, por isso as leis de reparação social, como as ações afirmativas, são conquistas relevantes.

Todos são iguais perante a lei, segundo o que preconiza o Art. $5^{\circ}$ da Constituição Federal, de 5 de outubro de 1988 (BRASIL, 1988). É preciso que haja intervenções para que esse artigo da CF seja garantido por causa desse contraste entre o que a legislação diz e o que os dados estatísticos demostram. Nessa perspectiva, somos concordantes com Fonseca (2009, p. 127), quando afirma que:

As ações afirmativas não estão fundadas em princípios revolucionários ou na constituição de uma nova ordem baseada em separações. Ao contrário, fundamentam-se na lógica da unidade e na diversidade de talentos para a produção cada vez maior de profissionais qualificados para atender ao mercado. As ações afirmativas visam à constituição de reformas estruturais na sociedade a fim de ampliar o número de indivíduos participantes da cidadania republicana, bem como o universo daqueles que participarão efetivamente da construção da nação.

As ações afirmativas são assim denominadas porque visam atender e reparar a situação de discriminação e de desigualdade de alguns grupos. Assim, para a nossa definição utilizaremos as palavras de Fonseca (2009, p. 11), que afirma que "[...] as ações afirmativas são políticas públicas destinadas a atender grupos sociais que se encontram em condições de desvantagem ou de vulnerabilidade social em decorrência de fatores históricos, culturais e econômicos".

Nesse processo, em 2010 é promulgada a versão definitiva do Estatuto da Igualdade Racial, sob a égide da Lei ${ }^{\circ} 12.288$, de 20 de julho de 2010 (BRASIL, 2010). O Estatuto é a efetivação de uma luta histórica. Movimentos, grupos e pessoas são o foco desse estatuto, que traz uma perspectiva sobre a população negra deste país, nas várias áreas e aspectos que compõem o cotidiano.

A Lei ${ }^{\circ} 12.990 / 2014$ (BRASIL, 2014) versa sobre a reserva aos negros $20 \%$ das vagas oferecidas nos concursos públicos no âmbito da administração pública federal, das autarquias, das fundações públicas, das empresas públicas e das 
sociedades de economia mista controladas pela União. No município de São Paulo, a Lei $\mathrm{n}^{\circ}$ 15.939, de 23 de dezembro de 2013 (SÃO PAULO, 2013), estabelece as cotas raciais na porcentagem de $20 \%$ para o ingresso de negras e negros no serviço público municipal em cargos efetivos e comissionados. Em 2016, houve o primeiro concurso para gestores escolares sob a égide da referida lei na cidade de São Paulo e uma aprovação de 5.999 diretores de escola e desses, 756 negros (pretos e pardos). No ano de 2017, houve a primeira convocação de 730 aprovados, sendo 230 negros. No Gráfico $1^{2}$, mostramos que, em 2018, tivemos $25,4 \%$ de diretores autodeclarados negros e indígenas, para aproximadamente $74,6 \%$ de brancos e amarelos num total de 1.242 autodeclarados.

Gráfico 1 - Diretores que se autodeclaram

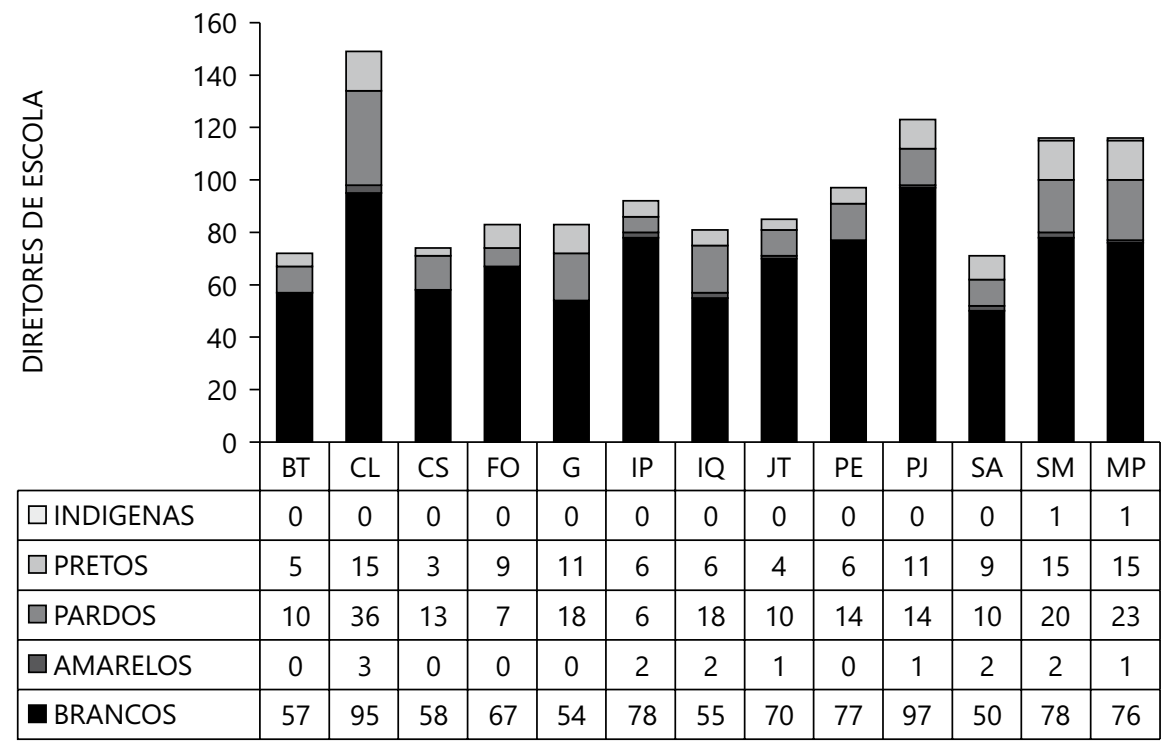

Diretorias Regionais de Educação - BT: Butantã; CL: Campo Limpo; CS: Capela do Socorro; FO: Freguesia do Ó; G: Guaianazes; IP: Ipiranga; IQ: Itaquera; JT: Jaçanã/Tremembé; PE: Penha; PJ: Pirituba/Jaraguá; SA: São Amaro; SM. São Mateus; MP. São Miguel Paulista.

Fonte: FERREIRA (2019).

Esses dados apresentados mostram como as diferenças quantitativas de diretores negros para diretores brancos são relevantes, e como a legislação, a aplicação de leis de reparação e as ações afirmativas são necessárias para pensarmos num quadro de equidade social.

\footnotetext{
2 http://dados.prefeitura.sp.gov.br/dataset/microdados- servidores- perfil. Acesso: 31 jul. 2018.
} 


\section{Histórias dos diretores escolares negros}

Após a aprovação do Comitê de Ética na Plataforma Brasil, parecer número 3.088.368 de 17/12/2018 e com a autorização dos(as) Diretores(as) Regionais para contatar os diretores escolares negros da rede municipal da cidade de São Paulo, iniciamos análise documental colhendo e pesquisando informações quase que diariamente do Diário Oficial da Cidade, organizamos uma base de dados que nos auxiliou a encontrar os diretores negros e ingressantes, que acessaram o cargo pela égide da Lei no ${ }^{\circ}$ 15.939/2013 (SÃO PAULO, 2013).

Ouvir as histórias e os relatos se tornou importante. Encontramos na metodologia da história oral e nos depoimentos base para o estudo a partir dos autores: Cruz Neto (1994), Nogueira (1973), Thompson (1992). A partir de então, foi possível desenvolver as estratégias para a utilização dos instrumentos metodológicos: entrevistas, análises documentais e observações de campo. Para análise das entrevistas, Bardin (2011) e Minayo $(2012,2014)$ afirmam que, de acordo com a metodologia que utilizamos, no nosso caso, história oral, devemos nos preocupar com a comunicação estabelecida com os sujeitos, por isso a importância de um roteiro, das perguntas e após essa coleta, a análise. Pela análise da enunciação, observamos cada entrevista singularmente e em sua totalidade, e, pela análise temática, fizemos alguns recortes e organizamos categorias de análise.

Entrevistamos seis diretores de escola, a maioria mulheres, todos autodeclados negros. Apesar da pesquisa não ter recorte na categoria gênero, os diretores de escola (homens) relataram que seu percurso como diretores foi marcado por desafios, porém, reconhecem que se fossem mulheres e negras esse percurso seria ainda mais complexo e difícil, assim como diz um dos diretores que participaram da entrevista:

[...] a sociedade é uma sociedade machista, patriarcal, ainda é; estão se modificando, as lutas estão todas aí, mas ainda é. Então, eu vou te dar um exemplo que aconteceu nessa semana: eu tive uma mãe que fez escândalo aqui na porta por causa do seu filho [...]. De manhã tinha uma Assistente de Diretor aí, eu geralmente faço uma parte do período da manhã, uma parte à tarde, um dia de manhã, um dia a tarde, para tentar atender aos dois turnos; e foi um escarcéu. Aí, a mãe sabia que minha Assistente era mulher e queria falar com a diretora, e ela não sabia que o diretor da escola era homem. Ouvindo a situação me levantei e saiu o diretor... mudou completamente a postura da mãe. E o que eu imagino que seja diferente sim a abordagem do feminino para o feminino, e do feminino para com o masculino, mas isso não é uma coisa da escola, tem que tomar cuidado com 
isso, porque não é da escola isso, é da sociedade, e escola não é um ser fora da sociedade, ela está inserida dentro da sociedade, então alguns hábitos e costumes que tem na sociedade, você carrega para dentro da escola (Relato do Diretor 5, 2019).

Nossas entrevistas aconteceram em diversas regiões da cidade de São Paulo: 3 na região norte, 1 na região nordeste, 1 na região do centro e 1 na região sul, e apesar de termos convidado 10 diretores para participar, somente 6 aceitaram o convite. Nosso objetivo era ouvir os diretores ingressantes, porém, no decorrer, sentimos a necessidade de ouvir também diretores escolares com mais experiência. Para a seleção, não pensamos em nenhum critério mais específico, pois nossa hipótese era a de que todos os diretores escolares negros teriam histórias relevantes sobre seu processo de construção identitária.

As entrevistas foram realizadas em um período de oito meses, caracterizadas, inclusive, pelas análises dos espaços, da estrutura e das atividades da gestão em conexão com a rotina escolar desse profissional. Ao adentrarmos em diversos espaços sentimos a escola em todas as suas nuances: os aspectos físicos do prédio, aspectos do fazer cotidiano com as crianças, e os profissionais que lá trabalhavam, a região onde estava localizada, o seu entorno, mas também fomos observados, uma experiência importante e significativa nesse processo.

Eu não tinha muito contato com os pais, aí, depois que eu passei a ser a Diretora e me livrei do trabalho burocrático, aí eu tinha tempo. E uma outra coisa que durante toda a vida eu gostei muito, muito, fazia muito eram as atividades de lazer para a criançada, porque lá não tinha nada; então fazia concurso, tínhamos desfile de passarela, juntava aquelas carteiras, amarrava os pés delas e as crianças desfilavam [risos]. Tinha a questão do esporte, tinha times, então o que o aluno queria fazer tinha margem para fazer, tinha os dançarinos que faziam os bailinhos e a criançada dançava. A criançada me amava; fora os passeios, porque a gente conseguia mandar para lugares como o Play Center naquela época. Então essas atividades todas que tinham na unidade pra criança era maravilha. Eu tinha uma fanfarra que ganhava prêmios... nossa, a criançada adorava; tinha uma mãe que cuidava da fanfarra, uma mãe, um pai que cuidava da horta. Tudo contava com a colaboração dos pais para ajudar na escola (Relato do Diretor 3, 2019).

Observamos nesse processo que os diretores de escola negros são minoria na rede municipal de Educação da cidade de São Paulo, ocupam o cargo por causa 
da aprovação no concurso público, e de uma legislação que transcende o racismo estrutural (ALMEIDA, 2019), desconstruindo a ideia que tenta aprisionar o negro a um lugar social de subalternidade.

Formulamos como hipótese que a ascensão dos negros na sociedade tem características peculiares devido à história de racismo, de preconceito e de discriminação (FONSECA, 2009). Tal hipótese se confirma com a leitura e com os diálogos que tivemos com os diretores de escola negros. No nosso caso, focamos essa questão na ascensão de negros no contexto da administração pública escolar, estudamos mais de perto e com mais profundidade a formação da identidade desse sujeito que, a nosso ver, é o mais importante desse processo social de afirmação na carreira do magistério.

Com as categorias de análise, essa perspectiva é mais evidente, assim na categoria 1 - "a infầncia, a família e a escola: representatividade e construção da identidade", buscamos na fala dos diretores as histórias das famílias, os ensinamentos que percorrem sua trajetória pessoal e profissional. Com o auxílio de autores como Almeida (2019), Hall (2014), Nogueira (2006), Santos, BS. (2003), Silva (2014), e dialogamos e pensamos na importância das famílias dos diretores nesse processo e como as lembranças da infância trazem relatos importantes de racismo, diferenças sociais e econômicas, as lutas do dia a dia para sobreviver em meio as dificuldades advindas do contexto de exclusão, e também alguns valores importantes que trazem junto de si advindos da vida, dos ensinamentos familiares, da escola e das relações que estabeleceram, citamos alguns como: perseverança, esperança, credulidade, vontade de ir à luta em busca dos sonhos, o respeito, entre outros.

A minha infância foi muito boa, meu pai é até hoje muito trabalhador e a gente conseguiu ter uma educação infantil e um ensino fundamental na escola particular. Foi com muito sacrifício que meu pai trabalhava dia e noite para garantir um bom estudo para mim e minha irmã. A escola era legal, porém por muitos anos eu e minha irmã éramos as únicas meninas negras e sempre éramos motivo de piada, comentários do tipo "como foi o fim de semana na favela", a gente não entendia por que isso acontecia. Porém conforme íamos estudando, e aprendendo história fomos percebendo como éramos diferentes (Relato da Diretora 1, 2019).

Eu tinha uma amiga na escola que era um pouco mais escura do que eu, a mãe dela era amiga da minha mãe e um dia fomos fazer tranças no cabelo, ficamos horas trançando. Era para um evento que 
aconteceria na escola, escolhemos as miçangas para colocar nas pontas, a minha era vermelha e da minha amiga era azul. Terminamos, estávamos nos achando lindas e fomos para escola. Quando a aula acabou a freira responsável falou que queria falar com a minha mãe, ela pediu para minha mãe retirar as tranças, pois a trança era sinal de falta de higiene e tinha mais possibilidade de pegar piolho. Depois do trabalho que deu para fazer, minha mãe passou a noite toda desmanchando o meu cabelo, foi muito dolorido e triste, depois desse fato nunca mais eu quis fazer trança no meu cabelo (Relato da Diretora 2, 2019).

Tais situações como as relatadas pelos diretores de escola causam consequências, porém também os auxiliam a encarar e a viver socialmente de maneira a não se vitimarem, e fazem questão de dialogar com os filhos e as crianças da escola, que é necessário encarar o racismo com dignidade e com conhecimento, sendo perspicaz para encararem as situações e não aceitar falsos elogios, não sendo condescendentes.

Na categoria de análise 2 - "a formação, a docência e a gestão escolar", utilizamos os autores Ezpeleta e Rockewell (1986), Gomes (1995, 1996), Paro (2010, 2015), Santos, BS (2010), para a compreensão acerca dos saberes entendendo-os como construção de saberes docentes e profissionais conforme nos ajudam a refletir Dubar (2012) e Pimenta (1997). Discutimos sobre o desafio dos diretores na formação inicial que teve como característica a permanência na escola quando eram estudantes, pois houve desafios marcantes, como a diretora que foi criada pela tia, e não podia tirar notas baixas, pois, se assim fosse, seria retirada da escola para trabalhar,

Com a morte do meu pai e o abandono da minha mãe, meus irmãos foram morar com meus avós e eu com minha tia-avó, que hoje tem 90 anos, lúcida. Na época a situação que já não era fácil, ficou ainda mais complicada. Minha tia dizia que se desse trabalho na escola, se ela fosse chamada pela segunda vez na escola, ela me tiraria da escola e me colocaria para morar e trabalhar em casa de família. Ela entendia que era importante estudar, então para quem se comportasse ela arrumava um emprego na casa de família, mas já avisava para a patroa que às cinco horas eu teria de sair para ir para escola. Assim, a partir da $5^{\circ}$ série, comecei no ensino noturno (Relato da Diretora 4, 2019).

A força, a crença das famílias e a ascensão social são relevantes, diante de tantas dificuldades da infância, assim como um relato de uma diretora que nos diz 
sobre a importância das mulheres de sua família - sua avó e sua mãe que eram lavadeiras, e que só conseguiu estudar porque sua avó lutou muito para que ela estudasse e recebesse ajuda da "caixa escolar" - benefício concedido por escolas aos alunos carentes e sem condições financeiras -, nos mostra que o processo para chegar a ocupar o cargo de diretor de escola não se limitou apenas a superação dos desafios, principalmente os sociais e os estruturais, mas a importância de fazer de sua rotina no cargo um processo coletivo de enfrentamento do racismo.

A categoria de análise 3 - "identidade étnica: ser negro e diretor de escola", organizamos uma confluência entre o que observamos no início do texto, com um aprofundamento nas questões sobre identidade. Os autores que nos auxiliaram nesse momento foram: Almeida (2019), Bento (2005), Gomes (1995, 1996), Hall (2014), Nogueira (1985, 1998, 2006), Ribeiro (2017), entre outros. Os seis diretores de escola que participaram da pesquisa se autodeclararam negros, e para confirmar a autodeclaração nos disseram que aspectos físicos justificaram tal afirmação, tais como: cabelo, cor da pele, formato do nariz e da boca, entre outros.

Porém, no decorrer das falas, observamos que não é possível se autodeclarar pertencente a uma determinada raça, sem ressaltar aspectos não tão visíveis, mas lembrados como a cultura, a história, as crenças, os valores que são transmitidos e ensinados por familiares.

Nossa! [risos] Eu diria que minha família é 100\% negra. 100\% porque toda a vida nós escutamos que nós éramos bonitos, fortes, corajosos, de falar que a gente era bonito, nós crescemos sabendo que o negro era bonito, era bonito. Até o cabelo... até a questão do cabelo, né?! Eu adorava o meu cabelo, mas sabe por que eu gostava? Minha mãe costumava, minha mãe e minha avó, porque cabelo "pixaim" é terrível, né?! [risos] Pegava toucinho, colocava pinga, para ele ficar molinho, e antes de passar o pente aqui, passava o toucinho no cabelo todo, e depois penteava e sempre ficava as pontinhas do toucinho com pinga, e eu ficava catando e comendo [gargalhada]. Então toda a vida eu gostei muito do meu cabelo, porque não era um cabelo só, era um cabelo com coisinha de pinga, aroma, sabor [risos] Então a identidade nossa foi sendo construída assim. Os negros são bonitos. A gente se achava bonito, e o povo não bancava a besta com a gente (Relato da Diretora 3, 2019).

Nesse relato observamos que essa diretora tem muito claro sua origem e sua história, porém o reconhecimento social é processual, cheio de situações de 
incredulidade e até desrespeito, incluindo ações ou omissões racistas. Os diretores em suas falas disseram que só estão hoje no exercício do cargo por causa de tudo que vivenciaram até aqui, das pessoas que conviveram, os ensinamentos que aprenderam nesse processo, e os desafios e obstáculos que enfrentaram e enfrentam constantemente.

Eu acho assim, as pessoas ficam cuidando da nossa vida, as pessoas nos julgam pelo que temos, como nos vestimos, e nos comportamos. Minhas tias me diziam que tinham melhores oportunidades quando bem vestidas, pois eram mais bem tratadas. Eu acredito que a sociedade não devia, mas é assim e nos cobra, para o nosso cargo público não precisa dessa aparência, porém quem nos procura espera alguém diferenciado seja a postura, a vestimenta, o trato faz toda a diferença. Estou aqui pela minha competência, mas se eu estiver vestida de qualquer jeito ninguém fala que sou diretora, certa vez estava na secretaria e uma pessoa no balcão pediu para falar com a diretora e quando disse que era eu, a pessoa me olhou com espanto chegando a arregalar os olhos de surpresa.

E a Diretora continua:

Bem no início do cargo, não sei se pela questão de ser negra, como eu não sou uma pessoa que já chega chegando, eu tive muita dificuldade das pessoas me reconhecerem como diretora. Então quando eu ia pelas primeiras vezes na DRE, as pessoas me perguntavam "você é o que na escola?", e isso de certa forma me ofendia, não que eu via nas pessoas a maldade, mas eu pensava "será que eu não tenho cara de diretora? Por que a pessoa precisa perguntar o que EU sou na escola? Será que eu não demonstro isso?". Isso pra mim era bem complicado [...]. Então isso foi muito difícil, e conseguir o respeito dos professores isso também foi bem difícil (Relato da Diretora 2, 2019).

A identidade do diretor de escola negro na cidade de São Paulo é a de um especialista social que conhece os dramas sociais, o que lhe faz ser um cidadão diferenciado, mais atuante e político em prol das pessoas e do território que trabalha, e esse reflexo é exaltado no seu cotidiano em uma permanente busca por uma escola que acolhe, que inclui e respeita as diferenças.

$\mathrm{Eu}$ tenho um trabalho que eu insisti muito que fosse colocado no Projeto Político Pedagógico da Escola, de uma escola mais humana, 
com todas as exigências técnicas dessas provas externas, que vem para a escola e a Emeftem muito dessas coisas, a questão do Ideb, mas assim, a vivência eu valorizo muito, a vivência de todos os autores que compõem a escola, a comunidade escolar, então os alunos em primeiro lugar, mas também os funcionários terceirizados, os funcionários concursados, a comunidade... eu tenho um modelo de escola, que foi a escola da minha vida. Então eu acredito muito na Pedagogia de Projetos e hoje aqui eu tenho 7 Projetos na escola, que passa pelo Futsal e Vôlei na área esportiva, eu tenho Teatro, eu tenho Flauta Doce nos dois primeiros anos e do terceiro ao nono eu tenho a banda, então eu ofereço música do primeiro ao nono ano, eu tenho as aulas de reforço de português e matemática, eu tenho nas "ondas do rádio" aqui [...]. Em função do conhecimento de nossa comunidade, a gente sabe que o melhor lugar para essas crianças estarem é aqui na escola [...]. Então quando você fala da minha atuação, a minha atuação, primeiro, é tentando manter o máximo possível a criança dentro da escola, criando um ambiente favorável para que o profissional trabalhe e que tenha, com isso, uma melhor condição de eles poderem oferecer para as crianças uma melhor aprendizagem (Relato do Diretor 6, 2019).

Observamos, então, que as ações desses diretores escolares negros que atuam em busca de mais oportunidades para as crianças, adolescentes e adultos fortalecem suas práticas identitárias e impactam o ambiente onde são produzidas, ou seja, é, a nosso ver, um ato específico e mais complexo de afirmação identitária que transcende o simples ato administrativo de gestão.

\section{Considerações finais}

Para esse artigo ressaltamos pontos importantes que encontramos no percurso com os autores com quem dialogamos e os diretores de escola que nos trouxeram para uma perspectiva muito além do que começamos. Ao retomarmos a pergunta que norteou a pesquisa - "Como é a trajetória identitária do diretor de escola negro quando num processo de assunção a um cargo de chefia" - observamos que esse processo, segundo os diretores que conhecemos e conversamos, foi marcado por muitas histórias e vivências importantes desde a infância, e que estar ocupando um cargo de chefia exige alguns saberes e a disposição para aprender e buscar caminhos para os desafios diários.

O diretor de escola negro, inserido nesse sistema de ensino, via concurso público, com as políticas de cotas raciais ou não, tem a sua atuação marcada 
pela incredulidade, a invisibilidade e ter suas ações subjulgada pelo preconceito. O negro na sua prática constrói sua identidade étnica e profissional revisitando sua história, mas principalmente busca estratégias para enfrentar o racismo e elabora expectativas de enfrentamento por meio dos documentos institucionais como o Projeto Político Pedagógico (PPP) e em ações que auxiliam a reflexão sobre os estudantes negros na escola. Apontamos essa hipótese como relevante, pois, conforme Souza (1983, p. 18), "ser negro [...] é sobretudo, a experiência de comprometer-se a resgatar sua história e recriar-se em suas potencialidades".

A luta pela preservação da identidade racial é processada juntamente com a constituição da identidade profissional. O enfrentamento do racismo se faz por ações construídas coletivamente no espaço escolar por meio da gestão democrática. As práticas antirracistas emergem nesse contexto impulsionando práticas e planos pedagógicos em que os educadores compreendam a importância da luta contra o racismo. 


\title{
Courses and trajectories: the identity of the black school director in municipal schools in the city of São Paulo
}

\begin{abstract}
This article is the result of research carried out in the field of Education, which was based on the study of a social phenomenon in the school environment, and investigated the identity trajectory of the black school director in municipal schools in the city of São Paulo. We used the oral history method, with the techniques of interviews and analysis of testimonies. We organized three categories of analysis: family and representation; teacher and manager training; and ethnic identity and administrative practice at school. We conclude that racism is experienced and faced by school directors and that they manage, despite this reality, to develop relevant work for the community where they work without victimizing themselves. Ethnic-racial identity becomes an instrument of struggle to legitimize fundamental elements for the constitution of their professional identity.
\end{abstract}

Keywords: Black. School Director. Identity. Affirmative Action Policies.

\section{Recorridos y trayectorias: la identidad del director de escuela negro en las escuelas municipales de la ciudad de São Paulo}

\section{Resumen}

Este artículo es el resultado de una investigación realizada en el campo de la Educación, que se basó en el estudio de un fenómeno social en el ámbito escolar e investigó la trayectoria identitaria del director de escuela negro en las escuelas municipales de la ciudad de São Paulo. Utilizamos el método de historia oral, con las técnicas de entrevistas y análisis de testimonios. Organizamos tres categorías de análisis, son: familia y representación; formación de profesores y directivos; e identidad étnica y práctica administrativa en la escuela. Concluimos que el racismo es vivido y enfrentado por los directores de escuela y que, a pesar de esta realidad, logran desarrollar un trabajo relevante para la comunidad donde trabajan sin victimizarse a si mismos. La identidad étnico-racial se convierte en un instrumento de lucha para legitimar elementos fundamentales para la constitución de su identidad profesional.

Palabras clave: Negro. Director de Escuela. Identidad. Políticas de Acción Afirmativa. 


\section{Referências}

ALMEIDA, S. L. Racismo estrutural. São Paulo: Pólen, 2019.

BARDIN, L. Análise de conteúdo. São Paulo: Edições 70, 2011.

BENTO, M. A. S. Branquitude e poder: a questão das cotas para negros. In: SANTOS, S. A. Ações afirmativas e combate ao racismo nas Américas. Brasília, DF: Ministério da Educação: UNESCO, 2005. p. 165-177.

BRASIL. Estatuto da igualdade racial: Lei no 12.288, de 20 de julho de 2010 e legislação correlata. 4. ed. Brasília, DF: Edições Câmara, 2015.

BRASIL. Lei n ${ }^{\circ} 9.394$, de 20 de dezembro de 1996. Estabelece as diretrizes e bases da educação nacional. Diário Oficial da União, Brasília, DF, 23 dez. 1996.

BRASIL. Lei ${ }^{\circ} 12.288$, de 20 de julho de 2010. Institui o Estatuto da Igualdade Racial; altera as Leis nos 7.716, de 5 de janeiro de 1989, 9.029, de 13 de abril de 1995, 7.347, de 24 de julho de 1985, e 10.778, de 24 de novembro de 2003. Diário Oficial da União, Brasília, DF, 21 jul. 2010.

BRASIL. Lei $\mathrm{n}^{\circ}$ 12.990, de 9 de junho de 2014. Estabelece reserva aos negros $20 \%$ (vinte por cento) das vagas oferecidas nos concursos públicos para provimento de cargos efetivos e empregos públicos no âmbito da administração pública federal. DF, 2014. Diário Oficial da União, Brasília, DF, 10 jun. 2014.

BRASIL. Senado Federal. Constituição da República Federativa do Brasil. Brasília, DF, 1988.

CRUZ NETO, O. O trabalho de campo como descoberta e criação. In: DESLANDES, S. F, et al. (orgs.). Pesquisa social: teoria, método e criatividade. Petrópolis: Vozes, 1994. p. 53-66.

DEPARTAMENTO INTERSINDICAL DE ESTATÍSTICA E ESTUDOS SOCIOECONÔMICOS - Dieese. O mercado de trabalho formal brasileiro: resultados da RAIS 2013. Nota Técnica, São Paulo, n. 140, set. 2014.

DUBAR, C. A socialização: construção das identidades sociais e profissionais. Porto: Porto Editora, 1997.

DUBAR, C. A construção de si pela atividade de trabalho: a socialização profissional. Cadernos de Pesquisa, São Paulo, v. 42, n. 146, p. 351-367, maio/ago. 2012. https://doi.org/10.1590/S0100-15742012000200003 
EZPELETA, J.; ROCKWELL, E. Pesquisa participante. São Paulo: Cortez, 1986.

FERREIRA, M. A. C. A constituição da identidade do Diretor de Escola de Educação Básica negro: articulações entre a identidade étnico-racial e a identidade profissional. Dissertação (Mestrado em Educação) - Centro de Educação e Ciências Humanas, Universidade Federal de São Carlos, São Carlos, 2019.

FERREIRA, N. T. Como o acesso à educação desmonta o mito da democracia racial. Ensaio: Avaliação, Políticas Públicas em Educação, Rio de Janeiro, v. 27, n. 104, p. 476-498, jul/set. 2019. https://doi.org/10.1590/S0104-40362019002701553

FONSECA, D. J. Políticas Públicas e ações afirmativas. São Paulo: Selo Negro, 2009.

GOMES, N. L. A mulher negra que vi de perto. Belo Horizonte: Mazza Edições, 1995.

GOMES, N. L. Educação, raça e gênero: relações imersas na alteridade. Cadernos Pagu, São Paulo, n. 6/7, p. 67-82, 1996.

HALL, S. Da diáspora: identidades e mediações culturais. In: SOVIK, L. R. (org.). Da diáspora: identidades e mediações culturais. 2. ed. Belo Horizonte: Editora UFMG, 2013. p. 326-391.

HALL, S. Quem precisa da identidade? In: SILVA, T. T. (org.). Identidade e diferença: a perspectiva dos estudos culturais. 14. ed. Petrópolis: Vozes, 2014. p. 103-133.

HELLER, A. O cotidiano e a história. 4. ed. Rio de Janeiro: Paz e Terra, 1970.

IBGE educa. Jovens. Matérias especial. Desigualdades sociais por cor ou raça no Brasil. Brasília, DF, 2020. Disponível em: https://educa.ibge.gov.br/jovens/ materias-especiais/21039-desigualdades-sociais-por-cor-ou-raca-no-brasil. html. Acesso em: 1 jun. 2020.

MINAYO, M. C. S. Análise qualitativa: teoria, passos e fidedignidade. Ciência \& Saúde Coletiva, Rio de Janeiro, v. 17, n. 3, p. 621-626, mar. 2012. https://doi.org/10.1590/S1413-81232012000300007

MINAYO, M. C. S. O desafio do conhecimento: pesquisa qualitativa em saúde. São Paulo: Hucitec., 2014. 
MUNANGA, K.; GOMES, N. L. O negro do Brasil de hoje. 2. ed. São Paulo: Global, 2016.

NOGUEIRA, O. Pesquisa social: introdução às suas técnicas. 2. ed. São Paulo: Nacional, 1973.

NOGUEIRA, O. Preconceito de marca: as relações raciais em Itapetininga. São Paulo: Edusp, 1998.

NOGUEIRA, O. Preconceito racial de marca e preconceito racial de origem: sugestão de um quadro de referência para a interpretação do material sobre relações raciais no Brasil. Tempo Social. São Paulo, v. 19, n. 1, p. 287-308, 2006. https://doi.org/10.1590/S0103-20702007000100015

NOGUEIRA, O. Tanto preto quanto branco: estudos de relações raciais. São Paulo: T. A. Queiroz, 1985.

PARO, V.H. A educação, a política e a adminsitração: reflexões sobre a prática do diretor de escola. Educação $e$ Pesquisa. São Paulo, v. 36, n. 3, p. 763-778, set./dez. 2010. https://doi.org/10.1590/S1517-97022010000300008

PARO, V. H. Crítica da estrutura da escola. São Paulo: Cortez, 2011.

PARO, V. H. Diretor escolar: educador ou gerente? São Paulo: Cortez, 2015.

PIMENTA, S. G. Formação de professores: saberes da docência e identidade do professor. Nuances, São Paulo, v. 3, n. 3, p. 5-14, set. 1997. https://doi.org/10.14572/nuances.v3i3.50

RIBEIRO, D. O que é: lugar de fala? Belo Horizonte: Letramento: Justificando, 2017.

SANTOS, B. S. A construção multicultural da igualdade e da diferença. Coimbra, Oficina do CES n ${ }^{\circ}$ 135, Centro de Estudos Sociais Colégio de São Jerónimo, 1999.

SANTOS, B. S. Para além do pensamento abissal: das linhas globais a uma ecologia de saberes. In: SANTOS, B. S.; MENESES, M. P. Epistemologias do Sul. São Paulo: Cortez, 2010. p. 23-72.

SANTOS, B. S. Reconhecer para libertar: os caminhos do cosmopolitismo multicultural. Rio de Janeiro: Civilização Brasileira, 2003. 
SANTOS, M. O lugar e o cotidiano. In: SANTOS, B. S.; MENESES, M. P. Epistemologias do Sul. São Paulo: Cortez, 2010. p. 584-602.

SÃO PAULO (cidade). Lei n ${ }^{\circ} 15.939$, de 23 de dezembro de 2013. Dispõe sobre o estabelecimento de cotas raciais para o ingresso de negros e negras no serviço público municipal em cargos efetivos e comissionados. DOC de 23/12/2013, p. 1. Disponível em: https://leismunicipais.com.br/a/sp/s/ sao-paulo/lei-ordinaria/2013/1593/15939/lei-ordinaria-n-15939-2013-dispoesobre-o-estabelecimento-de-cotas-raciais-para-o-ingresso-de-negros-e-negrasno-servico-publico-municipal-em-cargos-efetivos-e-comissionados. Acesso em: 15 dez. 2018.

SILVA, T. T. A produção social da identidade e da diferença. In: SILVA, T. T. (org.). Identidade e diferença: a perspectiva dos estudos culturais. 14. ed. Petrópolis: Vozes, 2014. p. 73-102.

SOUZA, N. S. Tornar-se negro: as vicissitudes da identidade do negro brasileiro em ascensão social. Rio de Janeiro: Graal, 1983.

THOMPSON, P. A voz do passado: história oral. Rio de Janeiro: Paz e Terra, 1992.

VASQUEZ, A. S. Filosofia da práxis. 2. ed. Rio de Janeiro: Paz e Terra, 1977.

ZUBARAN, M.; WORTMANN, M. L.; KIRCHORF, E. R. Stuart Hall e as questões étnico-raciais no Brasil: cultura, representações e identidade. Projeto História, São Paulo, n. 56, p. 9-38, maio/ago. 2016.

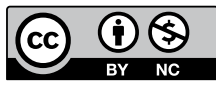

\section{Informação sobre os autores}

Douglas Aparecido de Campos: Doutor em Educação pela Universidade Federal de São Carlos com Pós-Doutorado pela Universidade de Coimbra. Professor Associado na Universidade Federal de São Carlos no Departamento de Metodologia de Ensino do Centro de Ciências Humanas, Centro de Estudos Sociais. Contato: profdouglas.eg@gmail.com

(iD) https://orcid.org/0000-0003-1190-7532

Maria Angélica Chagas Ferreira: Mestre em Educação pela Universidade de São Carlos pelo Programa de Pós-Graduação em Educação Profissional. Diretora de Escola Efetiva Cidade de São Paulo. Contato: angelicachagasf@gmail.com (iD) https://orcid.org/0000-0001-9334-9698 